\title{
O conde de Monte Cristo nos folhetos de cordel: leitura e reescrituras de Alexandre Dumas por poetas populares
}

\author{
IDELETTE MUZART - FONSECA DOS SANTOS
}

A LITERATURA DE mascate, de cordel ou folhas volantes, esteve provavelmente presente no Brasil, como no resto da América Latina, desde os tempos coloniais: documentos comprovam o embarque regular de pliegos sueltos para as colônias espanholas (1). Contudo, o primeiro folheto brasileiro, encontrado por Orígenes Lessa, é datado de 1865 e foi publicado no Recife. Escrito sobre o modelo de testamentos de animais, tão apreciados pela literatura de cordel portuguesa, ele contém alusões a acontecimentos da vida pernambucana que comprovam sua escritura brasileira (2). A partir de 1893, a literatura de folhetos constitui, aos poucos, um conjunto complexo e independente do sistema literário institucionalizado com seus poetas e suas editoras que, até os anos 1960, pertencem freqüentemente a poetas (3). Esta literatura tem suas próprias redes de comercialização (os mascates), sendo vendida nas feiras, nas estações ferroviárias e rodoviárias, e até nas ruas. Tem principalmente seu público leitor, que inclui iletrados e analfabetos, uma vez que a leitura comunitária, em voz alta, foi um dos meios privilegiados de sua transmissão tradicional. Este público diversificado identifica-se, direta ou indiretamente, com a cultura oral do Nordeste brasileiro.

\section{Adaptar romances para o folheto}

Desde o início, ao lado de narrativas oriundas da tradição oral (contos, lendas e anedotas) e de pelejas recriadas nos moldes das cantorias de repente, aparecem histórias inspiradas de textos escritos e, em particular, de romances e novelas dos séculos XIX e XX. Os poetas populares descobrem estas obras graças aos folhetins, publicados em grande número na imprensa, de 1850 a 1940, ou mediante edições populares das editoras Garnier ou Bertrand, quando se trata de livros traduzidos do francês. Entre as obras pertencentes a literaturas estrangeiras que foram reescritas em verso a partir 
de uma tradução anterior, e publicados em folheto, podemos citar $O$ violino do diabo e $O$ mártir do Gólgota, de Victor Pérez Escrich (4), A dama das camélias, de Dumas Filho (5), Notre Dame de Paris [O corcunda de Notre Dame] de Victor Hugo (6), Manon Lescaut, do Abade Prévost (7).

A influência do folhetim sobre a literatura de cordel, ainda em fase de emergência no Brasil, faz-se sentir no modo de divulgação das histórias. Em 1895, e pelo menos até 1915, Leandro Gomes de Barros publica suas histórias grandes em dois ou até três folhetos sucessivos. Um mesmo folheto contém freqüentemente o início de uma história e a conclusão de outra (8). Este constante entrelaçamento não parece perturbar a leitura e garante a continuidade da compra dos folhetos. Processos semelhantes podem ser observados nos primórdios do cinema.

O poeta, consciente de ser um intermediário cultural entre o mundo letrado e seu público popular, realiza um verdadeiro trabalho de adaptação e reelaboração, em particular no caso do romance. A adaptação, em primeiro lugar, resulta da escolha, numa obra longa e densa, dos episódios e das personagens que serão mantidos para que um romance de 500 ou 600 páginas seja reduzido a um folheto de 32 páginas, ou seja 159 sextilhas, sendo que a última corresponde geralmente à estrofe acróstica que serve de assinatura ao poema e constitui, via de regra, uma conclusão moralizadora. A reelaboração requer freqüentemente dois ou até três folhetos. Neste caso, torna-se importante manter a mesma capa (com um subtítulo esclarecedor) para que o público reconheça os diferentes volumes de uma mesma história: menções como "Continuação do $1^{\circ}$ volume" ou "Conclusão" articulam os diferentes volumes.

A reescritura impõe, por outro lado, uma versificação do texto que o modifica consideravelmente. Nos casos - raros - em que foi possível identificar com exatidão o hipotexto (9), foram encontrados trechos que não passavam de cópia versificada, versejada, do romance. Contudo, a reescritura pode incluir transformações mais importantes como mudanças de nomes de personagens ou adaptações inéditas à grafia portuguesa.

Entre os vários poetas populares que escolheram traduzir obras da literatura universal, para o leitor do folheto, está Maria das Neves Batista, uma das raras autoras de folhetos, que assinava com o apelido do marido, Altino Alagoano. Manifestava plena consciências do seu papel criador:

"Você sabe que o romance é feito numa literatura alta. O povo não entende, mesmo lendo não entende, não compreende e nem vai perder tempo para ler o romance. Então eu transformei aquela 
literatura no linguajar do povo, no modo que o povo fala, que o povo entende. (...) en peguei o miolo. A coisa mais, que me interessa. (...) O romance é o roteiro, agora aqui eu vou transferir toda essa história para o linguajar do povo e versar. (...) Eu não posso me afastar da linha do romance, eu posso criar, ajudar no mesmo sentido. (...) Então aqui neste romance $O$ Violino do Diabo ou o Valor da Honestidade, então, a lição que eu salientei neste romance, foi a honestidade da moça e do velho, entendeu? Que aquele homem fez toda a trapalhada, toda a trapaça para iludir esta moça. (...)" (10).

"Para fazer o folheto, eu leio a parte, analiso e formo o verso dentro daquela parte. Não vou ler todo o livro, eu leio aquela parte, aí vou fazendo os versos aos poucos conforme a leitura. $(\ldots) "(11)$.

"Muita coisa a gente tem que abandonar, a gente não pode pegar um romance e fazer ao pé da letra, tem que aproveitar o pensamento do escritor e transformar ao nosso pensamento, quer dizer, fazer aquilo de maneira que seja fiel: o histórico do escritor mais resumido" (12).

Tais palavras de Maria das Neves Batista são um dos raríssimos testemunhos de um poeta popular sobre esta recriação textual, poética e ideológica (13).

\section{O conde de Monte Cristo, um fenômeno editorial}

Este estudo nasceu do encontro com uma primeira e, logo após, uma segunda reescritura, em folheto, do mais famoso romance de Alexandre Dumas, O conde de Monte Cristo. Um segundo estudo está sendo desenvolvido sobre Os irmãos Corsos, do mesmo Dumas: trata-se novamente de uma história de vingança que não oferece contudo a riqueza de informações e possíveis confrontos de $\mathrm{O}$ conde de Monte Cristo.

Alexandre Davy de la Pailleterie (1802-1870), conhecido por Alexandre Dumas, conquistou a fama literária com seus dramas românticos (14), mas comprovou sua grande fecundidade e capacidade narrativa (com a ajuda de vários colaboradores, entre os quais Auguste Maquet) numa obra romanesca múltipla, publicada em folhetins e posteriormente em livros (15). Entre todas as obras de Alexandre Dumas, $O$ conde de Monte Cristo ocupa um lugar de particular destaque. Marlyse Meyer, no seu notável estudo sobre o folhetim, analisa o sucesso desta criação de Dumas desde a sua primeira 
publicação, em folhetins diários, com várias interrupções, no Journal des Débats, de 28 de setembro de 1844 a 15 de janeiro de 1846, ou seja, durante um ano e meio (16). Segundo a estudiosa,

"o sucesso [de Monte Cristo] é tal e a pressa em traduzir é tanta que a publicação [no Brasil, iniciada em 15 de junho de 1845, ou seja nove meses após o início na França] antecede a chegada do paquete. Lê-se no Jornal do Commércio, de 13 de agosto de 1845: 'Somos obrigados a suspender hoje a publicação de $O$ conde de Monte Cristo por não ter chegado ainda de Paris a continuação deste folhetim. Durante esta forçada interrupção, publicamos a Alameda das Viúvas' (...)" (17).

O folhetim de Dumas voltará e a publicação será finalmente encerrada no Brasil, após outras interrupções, em março de 1846, ou seja, dois meses apenas após o término da publicação francesa (18). Mas a paixão folhetinesca prossegue pelo século XX adentro e o mesmo O conde de Monte Cristo ainda está nos jornais de São Paulo em 1925. E, segundo Marlyse Meyer, citando Antonio Gramsci, “em 1930, para forçar a leitura do jornal, era preciso publicar em folhetim, O conde de Monte Cristo e Giuseppe Balsamo" (19).

Seria contudo apressado afirmar a origem exclusivamente folhetinesca da leitura de $O$ conde de Monte Cristo pelos poetas populares. O melodrama e o folhetim invadiram as telas desde os primeiros filmes, no tempo do cinema mudo, e muitos poetas populares encontraram neles tramas narrativas e personagens para suas histórias, bem como ilustrações para a capa das suas publicações. O folheto intitulado Os irmãos Corsos ou A fúria do vingador, por exemplo, apresenta-se desde o subtítulo explicativo, como um

"romance extraído do filme e livro do mesmo nome, aonde dois seres viveram uma só vida em dois corpos. O mais impressionante drama que a história registrou até os nossos dias. Sofrimento. Amor. Tragédia. Luta. Mistério. Ciência e Vitória” (20).

E a primeira estrofe reafirma suas fontes e seu objetivo:

"Vinde a mim meu santo Deus

para com francos esforços

eu escrever um romance

passado nos dias nossos

o qual Alexandre Dumas

intitulou "Irmãos Corsos" (21). 
De um modo ou de outro, a paixão do público por $O$ conde de Monte Cristo se mantém intacta após uma dezena de adaptações cinematográficas, sem contar as mais recentes para a televisão (22).

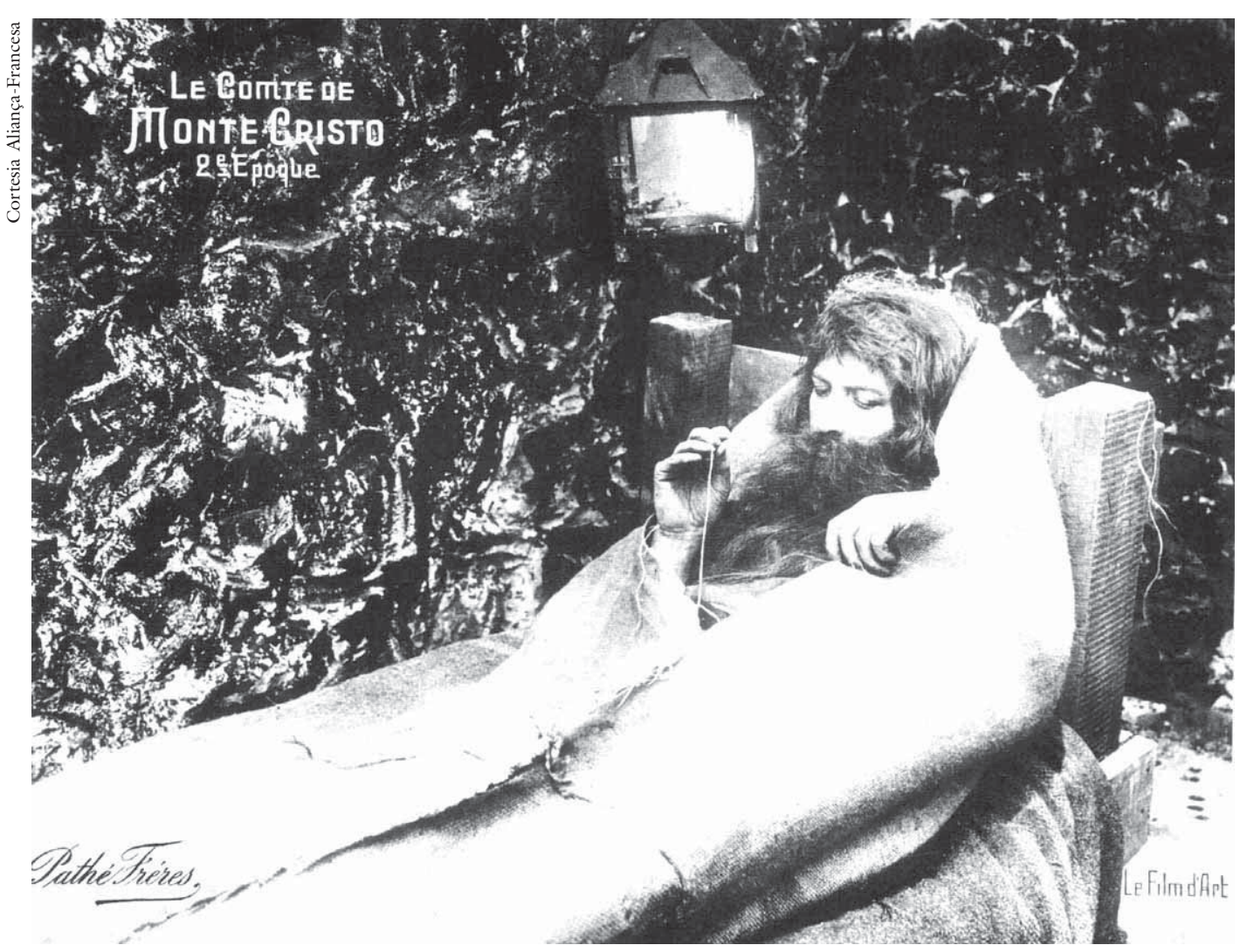

Cartaz do filme Le Comte de Monte-Cristo, de Henri Pouctal: a primeira versão da adptação francesa do romance de Alexandre Dumas foi exibida na Europa em 1918.

\section{Uma "tradução livre" de O conde de Monte Cristo}

Na literatura de cordel o sucesso de Monte Cristo pode também ser comprovado por um fato revelador: trata-se de um dos raros, senão o único romance a ter sido adaptado duas vezes.

A primeira adaptação deve-se ao poeta popular João Martins de Athayde (1880-1959) que começou a editar folhetos em 1908 e retirou-se 40 anos mais tarde. Tivemos acesso a reedições datadas de 1951 (23), para o primeiro volume, e de 1964, para os dois seguintes. Na ausência de qualquer referência à primeira edição, não foi possível determinar com exatidão a data de escritura deste texto. Outros dados, como o tipo de ilustração da capa por exemplo, permitem contudo situar, muito aproximativamente, o tempo da escrita entre 1920 e 1940. 
João Martins de Athayde inicia a adaptação a partir do título: O romance de um sentenciado (24). O longo subtítulo apresenta-se sob a forma de um resumo da narrativa, com evidente função comercial: trata-se de atrair e reter a atenção do comprador potencial anunciando em voz alta, na feira ou na rua, o título e subtítulo do folheto à venda.

“Exílio! Prisão! Sofrimento! Eis o que contêm as páginas desta comovente história de um belo e jovem marinheiro que, na hora do seu casamento, foi jogado na cadeia, inocente, passou 12 anos aprisionado numa célula da Fortaleza do Diabo. Mas a justiça do céu lhe concedeu a liberdade e ele se tornou o homem mais rico do seu tempo e se vingou dos seus algozes. Como realizou esta vingança?” (25).

A tendência aos títulos longos e detalhados caracteriza tanto a literatura de colportage européia quanto a brasileira. Assim, uma estudiosa do cordel espanhol no Século de Ouro, Maria Cruz Garcia de Enterría, cita um Memorial, de Lope de Vega, sobre a poesia vendida nas ruas de Madrid, que critica os títulos dos pliegos sueltos, "que dizem em prosa a súmula do que contêm seus versos" (26).

Se aproximarmos este resumo introdutivo da estrofe acróstica final, que assume também uma função de resumo,

" $A$ sorte de Vicenar

Teve muito precipício

$A$ mou, sofreu e vingou-se

I rradiou benefício

$D$ eus lhe ofertou Jaidê

$E$ m troca do sacrifício."

(Atayde, III, 48)

compreende-se então que João Martins de Athayde, como Maria das Neves Batista o explicava, procurou também o miolo da história, o que poderia tocar de perto a imaginação e a sensibilidade dos seus leitores e ouvintes. Desenvolveu, ou para falar a verdade, tentou conter esta rica matéria narrativa em três volumes de 48, 32 e 32 páginas respectivamente, num total de 532 sextilhas.

Se a capa não sofre alteração alguma, mantendo assim a unidade editorial dos três folhetos, o poeta distingue duas partes. A primeira corresponde ao primeiro volume sob o título de Romance do sentenciado : relata a história do jovem marinheiro de Marselha, sua prisão arbitrária, os anos de confinamento na cadeia, o encontro com um outro preso, sua evasão, a desco- 
berta do tesouro e a manifestação do poder e da riqueza na compra de um barco e de um título de nobreza. O volume termina pela volta à França e a reiteração da promessa de vingança. Interroga-se o narrador sobre o futuro da história (\$237-238) e o folheto termina pelo anúncio da continuação em outro volume:

"Se quer saber a resposta

e ficar maravilhado

procure ler $A$ vingança

do mesmo sentenciado."

O volume 2 intitula-se, de fato, $A$ vingança do sentenciado, assim como o volume 3, que acrescenta: Conclusão. Este segundo volume relata a entrevista do abade Busoni com Caderousse, a viagem do conde para a Grécia e o resgate de Jaidê, a volta à França após sete anos, a instalação em Paris onde o conde dá uma festa durante a qual reencontra sua antiga noiva, com o marido e o filho, e a amizade que nasce entre o conde e o jovem. Após a cena do teatro, na qual Jaidê reconhece o assassino do seu pai, a denúncia deste Par de França e o duelo impedido, começa o processo... mas chegamos à página 32 e a deposição de Jaidê é anunciada para o volume seguinte.

O terceiro volume, portanto, apresenta rapidamente o final do processo e a famosa cena de reconhecimento do conde por aquele que o traiu e que se suicida pouco depois. Passa-se então à vingança contra o juiz. Reencontramos os principais elementos narrativos presentes no romance de Alexandre Dumas: o filho natural tido por morto e que se tornou um bandido, sua utilização pelo conde, a composição da família do juiz. A ação, contudo, é simplificada e resumida: Jorge, o filho ignorado do juiz, torna-se noivo da filha deste mesmo juiz. A noiva morre envenenada no dia das núpcias, evitando assim o incesto. Jorge, denunciado, é preso e descobre na cadeia sua verdadeira identidade. Durante o processo, revela-se publicamente sua filiação, o juiz desesperado volta à casa onde encontra os corpos da esposa e do filho menor, mortos por veneno. $\mathrm{O}$ abade Busoni reaparece e a cena do reconhecimento repete-se. O juiz enlouquece. Os remorsos do conde, frente ao corpo da criança, são apagados pelo amor de Jaidê, interpretado como signo do perdão divino.

Esta adaptação manifesta portanto certa liberdade com relação ao romance inicial, como a supressão de personagens importantes: o armador Morel e a sua família - amigos e benfeitores de Edmond Dantès, protegidos e amigos do conde de Monte Cristo - ou Danglars, o terceiro membro do complô que mandou Dantès para a cadeia. Desaparecem também segmen- 
tos narrativos inteiros como a parte do romance de Dumas ambientada em Roma, bem como os diversos episódios do banco que constituíam a vingança do conde contra Danglars.

Por outro lado, certas personagens têm seu papel consideravelmente limitado - o pai do juiz, o velho bonapartista, presente na primeira parte e causa direta da prisão do jovem marinheiro, não aparece mais na história ou reduzem-se a simples suportes da ação. Tais transformações narrativas, bem como a mudança dos nomes das personagens, permitem a João Martins de Athayde manifestar livremente sua criatividade e dar outra significação ao Romance de um sentenciado.

O tempo do romance continua o mesmo, apesar de um anacronismo possivelmente involuntário:

"Foi em oitocentos e quinze

que essa história passou

tempo que na bela França

Luiz dezasseis reinou

Marselha a grande cidade

este drama apresentou."

Fora de Marselha e Paris, pólos espaciais da história, os principais topônimos são reinventados: assim o Château d'If torna-se Fortaleza do Diabo quando a tradução publicada em livro o chama de Fortaleza de If.

"Era um enorme rochedo

perdido no meio do mar

que causava horror e medo (...)

pra lá iam presos políticos

condenados ao degredo" $(\$ 87)$.

Esta "Fortaleza do Diabo" evoca o nome da ilha onde foi mantido preso o Capitão Dreyfus e talvez não seja um acaso: l'Affaire Dreyfus tinha sido amplamente comentado pela imprensa brasileira (27). O poeta poderia ter aproximado os dois heróis, ambos franceses, vítimas de uma acusação infundada e condenados injustamente à prisão e ao exílio. Lembramos as primeiras palavras do subtítulo: "Exílio! Prisão! Sofrimento!”. A aproximação realiza-se quase que naturalmente no imaginário, sem considerar a diferença entre o ser humano que se tornou personagem histórica e a personagem de papel. 
Por outro lado, uma alusão aos presos políticos poderia ser interpretada como uma referência direta à época particularmente perturbada dos anos 30 no Brasil quando as cadeias se encheram de presos políticos, dentre os quais alguns conheceram o exílio. Mas, na realidade, Athayde segue fielmente o texto do romance de Dumas, publicado em português por Bertrand e Aillaud, sem indicação de data mas certamente anterior a 1930 :

“(...) a cem toesas diante de si, viu erguer-se o rochedo negro e escarpado sobre o qual se levanta, como uma excrescência de pedra, a horrenda fortaleza de If. Essa forma singular, essa prisão em redor da qual reina tão profundo terror (...) Essa fortaleza é uma prisão de Estado, reservada para os maiores réus

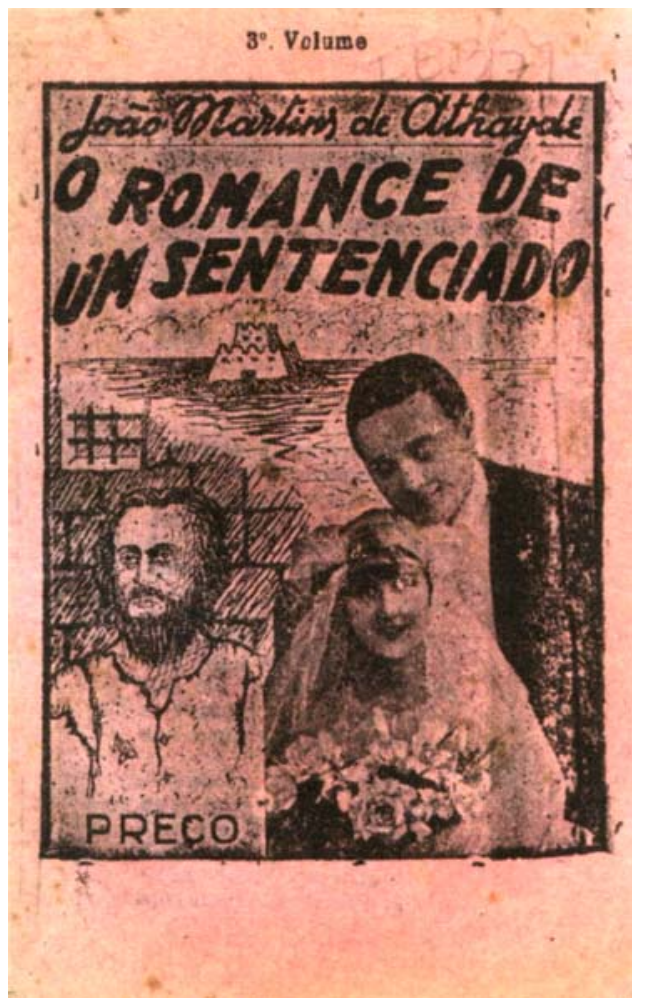

Fac-simile da capa de $\mathrm{O}$ romance de um sentenciado políticos (...)" (28)

Na descrição da fortaleza, por outro lado, usa de inúmeros superlativos que lembram a linguagem hiperbólica dos poetas populares na construção dos seus marcos poéticos (29):

“As paredes da prisão eram de enorme grossura ali os presos passavam as piores amarguras morriam sem ver a luz nas maiores das torturas" $(\$ 93)$.

A Ilha de Monte Cristo, onde o futuro conde encontra o tesouro anunciado, muda de nome e passa a chamar-se Ilha de Mirabou, situada pelo narrador na Ásia. A transformação não deixa de ser curiosa porque o poeta troca o topônimo sonoro e simbólico por um nome aparentemente francês e de pronúncia ambígua: Mirabou lembra Mirabô, Mirabeau. Por outro lado, troca a localização mediterrânea, espaço que o leitor de folhetos já conhece de muitas outras histórias, por uma Ásia mais distante ainda e 
imprecisa (30). De modo sincrético, o reino de Janina, na Grécia, assume o nome do pai de Haydée, Ali de Tebelen, e se confunde quase com o nome da ilha vizinha do Château d'If, Tiboulen. Assim, o espaço narrativo, tão preciso em Dumas, entra plenamente no imaginário: Tiboulen e Mirabou flutuam num mar de lenda, entre Marselha e um longínquo e misterioso Oriente.

João Martins de Athayde manifesta também uma grande fantasia na atribuição dos nomes próprios a suas personagens, preferindo inovar do que adaptar os nomes franceses. Em compensação, ele mantém os nomes italianos (Abade Busoni) ou orientais, mais exóticos: Haydée torna-se Jaidê, sua mãe é Valaquí, mas o sultão que compra Jaidê recebe um nome de produto químico, Niticida.

Qual o resultado desta simplificação da trama narrativa e das personagens? A personagem de Edmond Dantès (Ronaldo Vicenar) mantém-se no centro da narrativa. O primeiro volume mostra sua evolução física: o jovem e corajoso marinheiro de 18 anos

“(...) tipo perfeito

de beleza singular

alto, esbelto, insinuante

se pode até confessar

que o próprio Adónis podia

sua beleza invejar" ( $\$ 23)$.

Conserva, ao sair da cadeia, sua "extrema beleza" $(\$ 200)$, mas

"Agora seu olhar cansado

tinha um cunho de tristeza $(. .$.

em su'alma vicejava

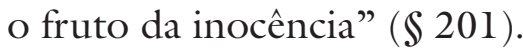

Se o herói é uma vítima ao longo do primeiro volume, o poeta insiste na sua transformação pelo sofrimento e o desejo de vingança, freqüentemente reiterado, até chegar a ser

$$
\begin{aligned}
& \text { “(...) um espectro } \\
& \text { de um ente desgraçado } \\
& \text { que o senhor sepultou } \\
& \text { [lhe] deixando encarcerado (...)” (III, } \$ \text { 126). }
\end{aligned}
$$


O poeta explica esta vingança longamente preparada e reorganiza a narrativa para inserir o inquérito na Grécia, o resgate de Jaidê e sua educação numa continuidade cronológica, em vez de recorrer à construção em flash-back como Alexandre Dumas. Finalmente, a dimensão providencial e o apoio divino à manifestação pública de sua inocência são reforçados por múltiplas alusões e comparações com o Cristo:

"mas nem o próprio Jesus

livrou-se do traidor" (II, $\$ 48$ ).

A dúvida sobre a legitimidade da vingança, frente ao corpo da criança envenenada:

“(...) e exclamou: oh! Jesus

vosso poder excedeu

do direito da vingança

perdoai o ódio meu!" (III, $\$$ 131).

desaparece, cinco estrofes depois, apagado pelo que se pode chamar de "triunfo do amor":

“- Jaidê, você me ama

sei que não fui castigado

da vingança que tomei

porque ainda fui lembrado

e por Deus pois ele fez

por um anjo ser amado" (III, $\$$ 136).

A supressão da personagem de Danglars teve como conseqüência o desaparecimento da crítica dos meios financeiros e a denúncia do poder do dinheiro, embora as primeiras estrofes incluíssem uma abertura filosófica sobre a corrupção dos homens pelo dinheiro.

Finalmente, as personagens femininas, Marluce (Mercedes) e Jaidê, apresentam-se como simétricas, no início e no final da narrativa, e suas descrições as tornam parecidas, embora a de Jaidê acentue a sensualidade da mulher oriental: simbolizam o amor perdido e reencontrado, a mulher - recompensa de uma longa demanda de que não era objeto mas somente testemunha.

O Romance de um sentenciado assume, portanto, na recriação de João Martins de Athayde, uma significação diferente do original: a vingança, anunciada no título da segunda parte, realiza-se sem nenhuma ação violenta 
do vingador, de modo oposto à prática narrativa do folheto, no qual as vinganças são sempre violentas, sangrentas e estendem-se freqüentemente às famílias e aos parentes. $\mathrm{O}$ tesouro encontrado na ilha serviu tão somente à revelação da verdade e esta verdade, ao ser dita, tornou-se uma arma contra a mentira e a traição. Os maus suicidam-se ou enlouquecem, os parentes envenenam-se ou fogem. O inocente triunfa sem remorso uma vez que o amor e a paz lhe são devolvidos, signo evidente da benção divina.

\section{Um digest indigesto de $O$ conde de Monte Cristo}

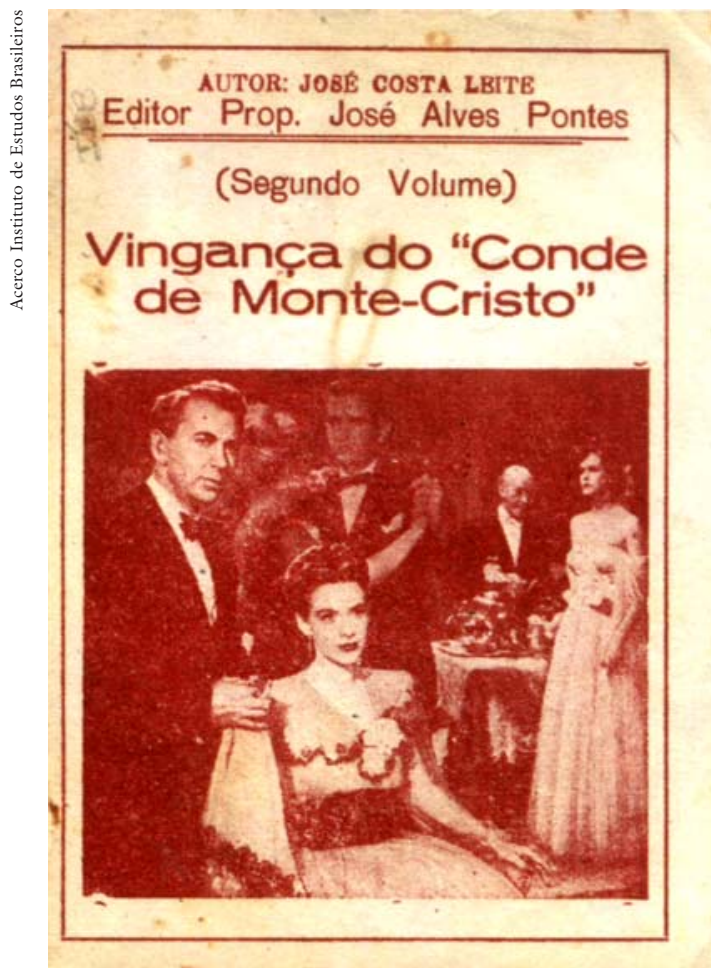

Fac-símile da capa de Vingança do "Conde de Monte-Cristo"

Em 12 de fevereiro de 1964, ou seja 25 ou 30 anos depois do Romance de um sentenciado, aparece o folheto intitulado $A$ vingança do "conde de Monte-Cristo” (Segundo volume) de José Costa Leite (1927), que se anuncia como continuação do Romance do "conde de Monte-Cristo”. Apesar de não-datada, a primeira parte foi provavelmente publicada pouco antes (31). A narrativa apresenta-se como a "Verdadeira história", pressupondo o tema conhecido do seu leitor e estabelecendo uma relação implícita com eventuais folhetos anteriormente publicados. Inicia o texto com duas estrofes exaltando a grandeza da verdade e o horror da mentira, oposição moral e metafísica que o relato pretende ilustrar. A referência ao livro de Dumas é evidente:

\footnotetext{
“Em 1815

N'um dia calmo e feliz

Chegou no porto em Marselha

Vindo de outro país

O navio Faraó

Assim a história diz:” (I, $\$ 4$ ).
}

A narrativa desenrola-se rapidamente e de modo muito resumido, com raras intervenções do narrador para sublinhar a importância de algum elemento do relato, como a carta entregue a Dantès, por exemplo, ou a explica- 
ção do termo bonapartista ao público leitor brasileiro que leva o autor a um anacronismo interessante e revelador da época de escritura do folheto (32):

"Portanto, naquele tempo

quem fosse bonapartista

a favor de Bonaparte

ficava logo em vista

odiado pelo povo

pior do que comunista” (I, $\$ 27)$.

Os nomes de personagens são mantidos, com uma única exceção: Haydée torna-se Suzette (33). O modo de resumir é tão drástico que raras seqüências conseguem escapar ou se desenvolver em mais de uma estrofe. Daí a importância particular das 14 estrofes dedicadas aos esforços de Dantès para realizar o túnel entre sua célula e a do abade Faria, quando o mesmo número de estrofes basta para relatar o restante dos 12 anos de cadeia de Dantès, até a morte do abade. Do mesmo modo, a evasão apresenta-se como um longo combate contra o mar, em que as características heróicas da personagem são exaltadas até o fantástico:

"Nadou quarenta e seis horas

o mar lhe fazendo guerra” $(\mathrm{I}, \mathbb{\$} 121)$.

O primeiro volume fecha-se sobre a transformação de Dantès em Monte Cristo e o segundo retoma o ritmo frenético do digest: o episódio de Roma não ocupa senão 10 estrofes e o resto da história precipita-se de tal modo que não podemos deixar de pensar a pertinência do comentário de Umberto Eco sobre a necessidade de detalhes e repetições no romance de Alexandre Dumas para produzir sentido (34).

José Costa Leite escreveu estes dois folhetos a partir de Alexandre Dumas, claro, como também a partir de João Martins de Athayde: em vários momentos, ele resume o folheto dos anos 30-40, restituindo mais ou menos os nomes originais e reinserindo o episódio de Roma. Lembramos que ele quer escrever a verdadeira história. Encontramos aqui, acolá, versos de Athayde mas, de modo geral, a língua é mais familiar e não deixa de estranhar ouvir, na boca de Villefort exigindo da sua esposa a verdade sobre o envenenamento de Valentina, uma ameaça formulada numa gíria violenta:

"conte a história direito

senão te meto o facão” (II, $\mathfrak{S} 146)$. 
A estrofe acróstica manifesta, mais claramente ainda do que no texto de João Martins, uma função moral e normalizadora:

"Já descrevi para o povo

$C$ omo a história passou-se

$O$ conde de Monte-Cristo

$S$ ofreu, mas depois vingou-se

Tendo Suzette nos braços

$A$ mou, lutou e casou-se" (II, $\$$ 159).

O texto termina por esta conclusão banal, onde as rimas (passou-se / vingou-se / casou-se) remetem ao tema do romance de amor contrariado, em que um casal deve enfrentar mil dificuldades antes de ver o amor triunfar. A antepenúltima estrofe corresponde à descrição do casamento de Monte Cristo com Suzette, com uma grande festa digna do final dos contos orais e uma comovente cena de amor conjugal:

"Suzette disse: - Querido

sem te beijar não resisto

e deu um beijo no rosto

do conde de Monte-Cristo" (II, $\$ 158$ ).

Como estamos longe de Monte Cristo, tanto o de Alexandre Dumas quanto do sentenciado de João Martins de Athayde! A história contada por José Costa Leite, de modo confuso e precipitado, revela-se chã e sem interesse. De resumos em generalizações, o autor conseguiu a proeza de desmontar a notável máquina romanesca que conquistou leitores do mundo inteiro e de transformá-la finalmente numa historieta de amor com toques de heroísmo e convenção.

\section{Metamorfoses de Monte Cristo}

A comparação dos dois folhetos, nascidos da leitura do romance de Dumas, pode ser completada pelo confronto das capas: o folheto de João Martins de Athayde apresenta uma montagem de dois desenhos - representando uma fortaleza no meio do mar e um homem barbudo, junto com a fotografia de um casal de noivos, provavelmente recortada de um cartão postal. A fotografia apresenta-se como um acréscimo posterior, tendo sido colada sobre o desenho inicial para esconder (imperfeitamente) a menção de preço (35). Trata-se portanto de uma ilustração adequada para o primeiro volume que foi mantida para os dois volumes de Vingança de um sentenciado pelos motivos comerciais já evocados. 
A capa do folheto de José Costa Leite é provavelmente uma fotografia de cinema, escolhida em função do gosto da época ou talvez, mais simplesmente ainda, por estar disponível no estoque da editora. Representa uma festa num ambiente rico e elegante, com um casal no primeiro plano. Poderia ilustrar a segunda parte do relato, mas não sugere um sentido ou uma orientação de leitura, como é o caso da maioria das capas de folheto, qualquer que seja o tipo de ilustração: desenho, foto, cartão postal, xilogravura (36).

Dessa forma, no texto como na capa, o folheto de 1964 não consegue uma verdadeira criação. Apesar de uma leitura mais cuidadosa e exata do romance de Alexandre Dumas, o poeta não soube compreender o miolo da história, o que fazia sua originalidade e lhe dava sentido. Servir-se do romance como de um plano, ou do risco do bordado, para criar ou recriar, respeitando sempre as regras impostas pela verossimilhança e a coerência narrativa, aquilo que Maria das Neves, na entrevista já citada, resumia pela expressão "ajudar no mesmo sentido", não obriga ao respeito da estrutura narrativa nem do perfil psicológico das personagens.

Assim, a vingança permanece o tema principal do Romance de um sentenciado:

"Amou, sofreu e vingou-se", afirma o folheto de João Martins de Athayde, contudo o autor não vacilou em reinterpretar, em "aproveitar o pensamento do escritor e transformar no [seu] pensamento, quer dizer, fazer aquilo de maneira que seja fiel", diria Maria das Neves Batista.

Por que esta transformação?

A vingança, segundo um outro leitor atento de Monte Cristo, Antônio Cândido,

“embora tão velha na literatura quanto a própria literatura, recebeu do romantismo alguns toques especiais. Não será excessivo lembrar que ela se tornou então um recurso de composição literária, de investigação psicológica, de análise sociológica e de visão de mundo. (...) A partir daí, pode-se aquilatar a importância dos romances sociais e folhetinescos, em que o ombro-aombro motivado pela vingança nivela a alta sociedade com o bas-fond, revolvendo na sua marcha, como um arado espectral, as consciências e os níveis sociais (37). 
A visão de Antônio Gramsci era muito mais severa quando qualificava Monte Cristo de

“o mais opiáceo dos romances populares: que homem do povo não acredita já ter sofrido uma injustiça por parte dos poderosos e não fantasia sobre uma 'punição' que lhes haverá de infligir? Edmundo Dantès oferece a este homem do povo um modelo, embriaga-o de exaltação, substitui a crença numa justiça transcendente na qual ele não acredita mais sistematicamente (38).

Precisamente o leitor/ouvinte de João Martins de Athayde acredita (ainda?) numa justiça imanente. A vingança que nos apresenta resulta de uma colaboração entre o homem e Deus: o homem propõe e Deus dispõe. Monte Cristo/Mirabou assume a função de deus ex-máquina, ele faz acontecer mas deixa aos homens a liberdade de agir. Frente a revelação da verdade - a verdadeira identidade de Monte Cristo/Mirabou - os maus morrem, enlouquecem ou fogem, como se estivessem frente à figura divina (39).

Mais do que a uma vingança tradicional, geralmente traduzida em violência e sangue, esta visão remete para outro tipo de narrativa tradicional, o da inocência reconhecida (40) que, a partir da lenda de Genoveva de Brabant, inspirou, direta ou indiretamente, a criação de numerosos folhetos da literatura de cordel: mulheres injustamente acusadas de adultério e, mais raramente, de outros crimes, que sofrem mil e um infortúnios, antes de sua inocência ser reconhecida e tornada pública graças à intervenção da Providência (41).

João Martins de Athayde efetua assim uma transposição cultural do romance de Alexandre Dumas. Adaptando-o à sua própria cultura, ele cria uma categoria híbrida que lhe permite responder satisfatoriamente tanto às exigências do modelo da vingança recebida de Dumas quanto às do triunfo da inocência nos moldes tradicionais. José Costa Leite, com menos talento talvez ou com mais pragmatismo, não fez outra coisa, todavia escolheu uma via mais empobrecedora e limitada.

A originalidade desta história de vingança sem violência aparente, preparada secretamente durante anos, antes de se realizar pela simples revelação da verdade, obrigou cada um dos poetas populares a reinterpretar a história, adaptando-a a modelos narrativos e ideológicos, herdados da tradição oral que constitui o fundo formador da literatura de cordel. A notável diferença de qualidade entre as duas reescrituras, além das qualidades poéticas intrínsecas de cada autor, pode também ser avaliada numa perspectiva histórica: nos aproximados 30 anos, que separam a escritura dos dois folhe- 
tos, a literatura de cordel passou do seu apogeu, enquanto produção destinada à leitura popular, à condição de quase curiosidade para pesquisador. $\mathrm{O}$ leitor de João Martins de Athayde recebia com entusiasmo uma história manifestando a intervenção da divina Providência na vida dos homens; o de José Costa Leite, talvez mais cético ou desenganado, se satisfaz com uma simples história de amor. A cultura popular nesses casos, como em muitos outros, manifesta sua notável capacidade antropofágica em absorver o que lhe seduz, apropriando-se disto ou rejeitando aquilo, enriquecendo constante e conscientemente seu mundo e sua linguagem.

Variantes dos nomes próprios

\begin{tabular}{|c|c|c|c|}
\hline Alexandre Dumas & Trad. Ed. Bertrand & $\begin{array}{c}\text { João Martins } \\
\text { de Athayde }\end{array}$ & José Costa Leite \\
\hline $\begin{array}{l}\text { Topônimos: } \\
\text { Marseille } \\
\text { Château d'If } \\
\text { Ile de Tiboulen } \\
\text { Ile de Monte-Cristo } \\
\text { Janina } \\
\text { Personagens: } \\
\text { Edmond Dantès } \\
\text { Abbé Faria } \\
\text { Abbé Busoni } \\
\text { Comte de Monte-Cristo } \\
\text { Monsieur Morel } \\
\text { Maximilien Morel } \\
\text { Julie Morel } \\
\text { Mercedès Herrera }\end{array}$ & $\begin{array}{l}\text { Edmundo Dantès } \\
\text { Abbade Faria } \\
\text { Abbade Busoni } \\
\text { Conde de Monte-Christo } \\
\text { Senhor Morel } \\
\text { Maximiliano Morel } \\
\text { Julia Morel } \\
\text { Mercedes }\end{array}$ & $\begin{array}{l}\text { Ronaldo Vicenar } \\
\text { Abade Colozo } \\
\text { Abade Busoni } \\
\text { Conde de Mirabou } \\
\quad \text { x } \\
\text { x } \\
\text { x } \\
\text { Marluce }\end{array}$ & $\begin{array}{l}\text { Edmundo Dantês } \\
\text { Abade Faria } \\
\text { Abade Busoni } \\
\text { Conde de Monte-Cristo } \\
\text { x } \\
\text { x } \\
\text { x }\end{array}$ \\
\hline $\begin{array}{l}\text { Comtesse de Morcerf } \\
\text { Fernand Mondego } \\
\text { Comte de Morcerf } \\
\text { Albert Mondego } \\
\text { Vicomte de Morcerf } \\
\text { Caderousse } \\
\text { La Caronte, } \\
\text { femme de Caderousse } \\
\text { Gérard Noirtier } \\
\text { de Villefort }\end{array}$ & $\begin{array}{l}\text { Condessa de Morcerf } \\
\text { Fernando Mondego } \\
\text { conde de Morcerf } \\
\text { Alberto Mondego } \\
\text { Visconde de Morcerf } \\
\text { Caderousse } \\
\text { A Caronta } \\
\text { Gerardo N. } \\
\text { de Villefort }\end{array}$ & $\begin{array}{l}\text { Condessa Néde } \\
\text { Gustavo Gaspar } \\
\text { conde Néde } \\
\text { Roberto } \\
\text { homem do hotel } \\
\qquad \mathrm{x} \\
\text { Julio Salgado } \\
\text { Presidente do Tribunal }\end{array}$ & $\begin{array}{l}\text { Mercedes } \\
\text { Fernando } \\
\text { conde de Morcerf } \\
\text { Conde Alberto } \\
\text { Caderousse } \\
\text { Marama }\end{array}$ \\
\hline $\begin{array}{l}\text { Noirtier } \\
\text { Valentine de Villefort } \\
\text { Héloïse de Villefort } \\
\text { Edouard de Villefort }\end{array}$ & $\begin{array}{l}\text { Noirtier } \\
\text { Valentina de Villefort } \\
\text { Heloísa de Villefort } \\
\text { Eduardo de Villefort }\end{array}$ & $\begin{array}{l}\text { Bento Salgado } \\
\text { Inez } \\
\text { Tereza } \\
\text { Eduardo } \\
\text { Juiz Amaral Braga } \\
\text { interroga Jorge } \\
\text { no tribunal }\end{array}$ & $\begin{array}{l}\text { Marechal Venâncio, } \\
\text { Venâncio Noirtier. } \\
\text { Valentina } \\
\text { Celina } \\
\text { Eduardo }\end{array}$ \\
\hline Danglars & Danglars & $\mathrm{x}$ & Danglars \\
\hline $\begin{array}{l}\text { Hermine de Salvieux } \\
\text { Danglars }\end{array}$ & $\begin{array}{l}\text { Hermínia de } \mathrm{S} . \\
\text { Danglars }\end{array}$ & $\mathrm{x}$ & $\mathrm{x}$ \\
\hline $\begin{array}{l}\text { Eugénie Danglars } \\
\text { Benedetto }\end{array}$ & $\begin{array}{l}\text { Eugênia Danglars } \\
\text { Benedetto }\end{array}$ & Jorge $^{\mathrm{x}}$ & $\begin{array}{c}\mathrm{x} \\
\text { Benedito }\end{array}$ \\
\hline $\begin{array}{l}\text { (Andrea Cavalcanti) } \\
\text { Franz de Quesnel }\end{array}$ & $\begin{array}{l}\text { (André Cavalcanti) } \\
\text { Franz de Quesnel }\end{array}$ & (Renato Teles) & $\begin{array}{l}\text { (conde Benedito) } \\
\text { Roberto }\end{array}$ \\
\hline Baron d'Epinay & Barão de Epinay & $\mathrm{x}$ & o barão \\
\hline Luigi Vampa & Luigi Vampa & $\mathrm{x}$ & ladrões \\
\hline $\begin{array}{l}\text { Haydée } \\
\text { Ali de Tebelen }\end{array}$ & $\begin{array}{l}\text { Haydée } \\
\text { Ali-Tabelin }\end{array}$ & Jaidê & Suzette \\
\hline Sultan de Janina & Pachá de Janina & Sultão Tabelen & o sultão \\
\hline Vasiliki & Vasiliki (Vasikí) & Valaquí & esposa \\
\hline $\begin{array}{l}\text { Sultan Mahmoud } \\
\text { Jacopo, marin ami de }\end{array}$ & Sultão Mahmoud & Sultãa Niticida & $\mathrm{x}$ \\
\hline $\begin{array}{l}\text { Dantès } \\
\text { Bertuccio, serviteur } \\
\text { de Monte-Cristo } \\
\text { Ali, esclave muet de }\end{array}$ & Bertuccio & José & empregado \\
\hline Monte-Cristo & Ali & $\mathrm{x}$ & $\mathrm{x}$ \\
\hline
\end{tabular}

Nota. Os nomes completamente transformados estão em itálico. 
Notas

1 Cascudo, 1978, p. 198.

2 Silva, 1993.

3 Santos, 1997.

4 Altino Alagoano [pseudônimo de Maria das Neves Batista Pimentel], O Violino do diabo ou O valor da honestidade, cf. Mendonça, 1993; Manoel Apolinário Pereira, $A$ vida do juden errante, sem lugar, sem ano (Coleções de literatura de cordel do Instituto de Estudos Brasileiros da Universidade de São Paulo): “Tirei do Martir do Golgota / um romance interessante / de Samuel Belibeth / soldado e negociante / que se intitula a / Vida do Judeu Errante".

5 João Martins de Athayde, A Dama das Camélias, Recife, João Martins de Athayde, 18.07.1938 (Fonds Raymond Cantel de Littérature de Cordel n. 2517, Université de Poitiers).

6 Altino Alagoano [Maria das Neves Batista Pimentel], O Corcunda de Notre Dame, Recife, sem data, Pimentel \& Cia, sem data (Fonds Raymond Cantel de Littérature de Cordel n ${ }^{\circ} 2468$, Université de Poitiers); $2^{\mathrm{e}}$ ed. Belém, Guajarina, 20.6.1941 (Coleção Vicente Sales, Museu da Universidade Federal do Pará); reproduzido, com a autorização da autora, in: Mendonça, 1993, p. 233-240.

7 Altino Alagoano [Maria das Neves Batista Pimentel], O Amor nunca morre, João Pessoa, 22.9.1938, in: Mendonça, 1993, p.221-232.

8 Leandro Gomes de Barros, O Dez-Réis do Governo, Conclusão da Mulher Roubada, Manuel de Abernal e Manuel Cabeceira, Recife, 1907, in: Literatura Popular em Verso, Antologia, t. V - Leandro Gomes de Barros, 3, 1980, p. 39-56; Leandro Gomes de Barros, A Festa do Mercado do Recife [contendo A Festa do Mercado do Recife, A Índia (continuação)], in: Literatura Popular em Verso, Antologia, t. V - Leandro Gomes de Barros, 3, 1980, p. 191-208.

9 Segundo a terminologia de Gérard Genette, 1982.

10 Mendonça, 1993, p. 71. O sublinhado é nosso.

11 Id., ibid., p. 72.

12 Id., ibid., p. 74

13 Filha do poeta Francisco Chagas Batista, irmã e prima de poetas populares e estudiosos de cordel, nunca deixou de manifestar, até o final de sua vida, sua paixão pela poesia: "Eu sou filha de poeta / E neta de repentista / Meu avô era Ugolino / E meu pai Chagas Batista / Também faço poesia / O poeta é um artista”. Citado por Mendonça, 1993, p. 86.

14 Henri III et sa cour (1829), Antony (1831), La Tour de Nesle (1832), Kean ou Désordre et Génie (1836). 
15 Le Comte de Monte-Cristo (1844), Les Trois Mousquetaires (1844), Vingt ans après (1845), La Reine Margot (1845), La Dame de Monsoreau (1846), Les Quarante-cinq (1846-1848), Joseph Balsamo (1846-1848), Le Vicomte de Bragelonne ou Dix ans plus tard (1848-1850), Le Collier de la Reine (18491850), Ange Pitou (1851), La Comtesse de Charny (1852-1855), entre outros. Cf. Alexandre Dumas, un aventurier de génie, CD-Rom Littéraire [com mais de 50 obras em texto integral], Paris, Acamédia, 1993.

16 Meyer, 1996, p. 61-62.

17 Id., ibid, p. 287-288.

18 Id., ibid, p. 288.

19 Antonio Gramsci, Letteratura e vida nazionale, p. 357, apud Meyer, 1996, p. 370 .

20 Manuel Pereira Sobrinho, Os Irmãos Corsos ou A Fúria do Vingador [título da capa mas, na primeira página, os dois segmentos estão invertidos: A Fúria do Vingador ou Os Irmãos Corsos]. Recife, Editor-proprietário João José Silva, sem data (Fonds Raymond Cantel de Littérature de Cordel n. 2999, Université de Poitiers).

21 Id., ibid, p.2.

22 Sendo a última, uma adaptação bastante livre de Didier Decoin, para a televisão francesa, em 1998, com Gérard Depardieu no papel título.

23 Podemos afirmar que se trata de uma reedição por ser publicada por José Bernardo da Silva, de Juazeiro do Norte, Ceará, que tinha comprado os direitos editoriais do conjunto dos folhetos de João Martins de Athayde quando este se retirou, em 1949. Por folhetos de João Martins de Athayde, entende-se as obras escritas por ele ou cujos direitos tinham sido adquiridos por ele, como por exemplo as obras de Leandro Gomes de Barros.

$24 \mathrm{Na}$ nomenclatura funcional da literatura de folhetos, o termo romance designa um livrinho com um número de páginas igual ou superior a 24 , enquanto o termo folheto é reservado às obras de 8 ou 16 páginas (Souza, 1976, p. 13).

25 Athayde, 1951, I: ( ( ${ }^{\circ}$ v., $1^{a}$ estrofe).

26 Garcia de Enterría, 1971, p. 142. A mesma estudiosa nota a evolução crescente dos pliegos sueltos em tamanho e complexidade no final do século XVII, evolução que atribui à influência do barroco ambiente sobre o cordel.

27 Alfred Dreyfus (1859-1935), oficial francês de origem judaica, foi acusado em 1894 de traição e condenado à deportação na Ilha do Diabo, em Guiana. Poucos anos depois, revelou-se a culpabilidade de outro oficial que foi julgado e liberado em conseqüência de pressões diversas dos grupos anti-semitas. Emile Zola publicou uma carta aberta (J'accuse) tomando a defesa de Dreyfus. Este foi liberado em 1899 e definitivamente inocentado em 1906. L'Affaire Dreyfus dividiu a opinião francesa e teve grande repercussão internacional. 
28 Dumas, s.d., I:64.

29 Marcos, Castelos, Fortes ou Fortalezas são os nomes destas construções poéticas que os repentistas e, posteriormente, os poetas elaboravam em verso para manifestar e ilustrar simbolicamente sua capacidade poética. Deviam ser capazes de resistir às investidas poéticas de qualquer contendor. João Martins de Athayde escreveu o Marco do Meio Mundo em torno de 1915 ["Eu construí este marco / de um baobab estrangeiro / do cume delle se avista / São Paulo e Rio de Janeiro / a Itália e Allemanha / Suissa, França e Hespanha / Portugal sendo o primeiro"] e Leandro Gomes de Barros the respondeu com o folheto Como derribei o Marco do Meio Mundo, publicando a seguir o seu próprio Marco Brasileiro. Almeida-Alves Sobrinho, 1981, p. 83-150.

30 O poeta pode ter encontrado o nome no próprio romance de Dumas. No capítulo 113 [O passado], Monte Cristo volta ao Château d'If e pergunta ao vigia do castelo, que deixou de ser cadeia: "Conte-t-on quelques histoires sur ce château autres que celle de l'emprisonnement de Mirabeau" (Dumas, 1993, p. 1159). A referência foi mantida na tradução portuguesa (Dumas, s.d., IV, p. 276).

31 Caso as duas partes fossem publicadas com meses ou anos de intervalo, o autor teria sentido a obrigação de iniciar o segundo volume com um resumo ou pelo menos uma introdução explicativa. Ora, uma única estrofe estabelece o elo entre os dois volumes. A separação em dois volumes resulta portanto de uma simples obrigação editorial: são dois volumes de 159 sextilhas e 32 páginas cada.

$32 \mathrm{O}$ golpe instituindo um regime militar no Brasil interveio poucas semanas depois da publicação deste folheto. O termo comunista era então utilizado para designar qualquer pessoa com preocupações de justiça social, independentemente de pertencer ou não a um determinado partido.

33 Homenagem às Crèpes Suzette, sobremesa famosa da culinária francesa?

34 "Se Dumas tivesse sido pago não por linha 'a mais', como o foi, mas por linha 'a menos', ou seja se tivesse escrito um romance curto, seria ainda $O$ conde de Monte-Cristo esta fantástica máquina romanesca? (...) O romance de Dumas é uma máquina de produzir agonia, e não importa a qualidade dos gemidos e sim a sua quantidade" (Eco, 1993, p. 101).

35 A partir dos anos 20 e até os anos 50, o desenho foi a ilustração favorita do folheto e teve seus artistas, em particular Antônio Avelino da Costa, que assinava Avelino e ilustrou a maior parte dos folhetos de João Martins de Athayde, de 1918 a 1940, entre os quais $O$ namoro de um cego com uma melindrosa da atualidade, Descrição da mulher conforme os sinais, História de João da Cruz, História do boi misterioso, A morte de Alonso e a Vingança de Marina, ou ainda A princesa Rosa Mundo ou A morte do gigante (Souza, 1981, p. 35). A ilustração do Romance de um sentenciado apresenta muitos elementos semelhantes à de A princesa Rosa Mundo: traços, organização do espaço e montagem misturando desenho e cartão postal (Santos, 1993). 
36 Santos, 1997, p. 83-90.

37 Cândido, Tese e antitese, p. 15-16.

38 Antonio Gramsci, Letteratura e vida nazionale, p. 117-21, apud Meyer, 1996, p. 412.

39 Ver Psalmos, 68, por exemplo.

40 L'innocence reconnue é o título de um livro da literatura de mascate (littérature de colportage) na França. Cf. Bollême-Andriès, 1983, p. 237-335.

41 Entre as histórias mais conhecidas na literatura de cordel, estão: Os martírios de Genoveva, atribuído a Leandro Gomes de Barros ou José Galdino da Silva Duda, cf. Literatura Popular em Verso, Antologia, t. 1, 1964, p. 29-56; História da Imperatriz Porcina, de Francisco Chagas Batista, cf. Cascudo, 1979; História de Bernardo e Dona Genevra, de José Galdino da Silva Duda, Belém, Guajarina, s.d. Ver o estudo ainda inédito de Idelette Muzart-Fonseca dos Santos, "L'héroïsme féminin dans la littérature de cordel brésilienne: Geneviève de Brabant et les femmes persécutées", Bibliothèque blene et littératures de colportage, Colloque universitaire international, 12-13 novembre 1999, Troyes, Bibliothèque municipale de Troyes / Ecole Nationale des Chartes.

\section{Referências bibliográficas}

Os textos analisados

ATHAYDE, João Martins de. O romance de um sentenciado. José Bernardo da Silva (ed.). Juazeiro do Norte, Typographia São Francisco, 23.2.1951. 48 p. (Capa ilustrada por desenho e cartão postal recortado, sem assinatura). Coleção pessoal de Roberto Benjamin, Recife, PE, 1951.

A vingança de um sentenciado, $2^{\circ}$ v. José Bernardo da Silva (proprietário). Juazeiro do Norte, Typographia São Francisco, 31.1.1964. 32 p. (Capa idêntica ao folheto anterior e ostentando como título $O$ romance de um sentenciado, $2^{\circ} \mathrm{v}$ ) IEB-USP, 1964.

A vingança de um sentenciado, Conclusão. José Bernardo da

Silva (proprietário). Juazeiro do Norte, Typographia São Francisco, 28.1.1964. $32 \mathrm{p}$. (Capa idêntica ao folheto anterior e tendo como título $O$ romance de um sentenciado, $3^{\circ}$ v.) IEB-USP, 1964.

DUMAS, Alexandre. Le comte de Monte-Cristo. Edition établie par Claude Schopp, comprenant un Dictionnaire des Personnages, documents, index des lieux et bibliographie. Paris, Robert Laffont (Collection Bouquins), 1502 p., 1993.

O conde de Monte-Christo. 2 ed. Paris/Lisboa/Rio de Janeiro, Lib. Aillaud et Bertrand/Liv. Francisco Alves [Coleção Popular]. 4 v.: I, chap. 1- 
29, 258 p; II, chap. 30-52, 296 p.; III, chap. 1 (Roberto do Diabo)-29, 308 p.; IV, chap. 30-65, 321 p. (Capa ilustrada por um desenho de Moraes, com indicação do preço: 200 réis), s.d.

LEITE, José Costa. Romance do "Conde de Monte-Cristo". Alves Pontes (editorproprietário). Guarabira, Folhetaria Pontes, s.d. 32 p. (Capa ilustrada por fotografia de cinema e com a menção Romance do "conde de Monte-Cristo" bem como o nome do autor e do editor-proprietário). Fonds Raymond Cantel de Littérature de Cordel, FRC 4295, Centre de Recherches Latino-Américaines, Université de Poitiers.

A vingança do "Conde de Monte-Cristo". José Alves Pontes (editor-proprietário). Guarabira, Folhetaria Pontes, 12.2.1964, 32 p. (Capa idêntica ao folheto anterior com o título Vingança do "Conde de Monte-Cristo", segundo volume). Fonds Raymond Cantel de Littérature de Cordel, FRC 475, Centre de Recherches Latino-Américaines, Université de Poitiers.

\section{Obras e artigos críticos}

Alexandre Dumas, un aventurier de génie, CD-Rom Littéraire (com mais de 50 obras em texto integral), Paris, Acamédia, 1993.

ALMEIDA, Átila \& ALVES Sobrinho, José. Dicionário bio-bibliográfico de repentistas e poetas de bancadas, 2 v. João Pessoa, Editora Universitária, UFPB, 1978.

Romanceiro popular nordestino: Marcos e vantagens, 1. Campina Grande, Universidade Federal da Paraíba, 1981.

BOLLÊME, Geneviève \& ANDRIÈS, Lise (orgs.). Les contes bleus. Paris, Montalba, Collection Bibliothèque Bleue, 1983.

CANDIDO, Antônio. De la vengeance: sur le comte de Monte-Cristo. In: L'Endroit et l'Envers, essais de littérature et de sociologie. H.S. Becker (sélection et présentation). Trad. Jacques Thiériot. Paris, Métailié/Unesco, 1995, p. 4769.

CASCUDO, Luís da Câmara. Literatura oral no Brasil, 2 ed. Rio de Janeiro, José Olympio, 1978.

Os cinco livros do povo, $2^{\mathrm{e}}$ ed. João Pessoa, Editora Universitária/UFPB (edição fac similar), 1979.

ECO, Umberto. Eloge de Monte-Cristo. In: De superman au surhomme. Trad. Myriem Bouzaher. Paris, Grasset, 1993, p. 85-102.

FAUSTO, Boris. História do Brasil, $2^{\mathrm{e}}$ ed. São Paulo, Editora da Universidade de São Paulo/Fundação do Desenvolvimento da Educação, 1995. 
GARCIA DE ENTERRIA, Maria Cruz. Un Memorial casi desconocido de Lope de Veja. Madrid, Boletin de La Real Academia Española, n. 51, p. 139-160, 1971 .

Sociedad y poesia de cordel en el barroco. Madrid, Taurus, 1973.

GENETTE, Gérard. Palympsestes. Paris, Seuil, 1982.

Literatura popular em verso, Antologia, t. 1. Rio de Janeiro, Ministério da Educação e Cultura/Casa de Rui Barbosa, 1964, p. 29-56.

Literatura popular em verso, Antologia, t. V - Leandro Gomes de Barros, 3. Rio de Janeiro/João Pessoa, Ministério de Educação e Cultura/ Fundação Casa de Rui Barbosa/ Universidade Federal da Paraíba, 1980.

MENDONÇA, Maristela Barbosa. Uma voz feminina no mundo do folheto. Brasília, Thesaurus, 1993.

MEYER, Marlyse. Folhetim, uma história. São Paulo, Companhia das Letras, 1996.

SANTOS, Idelette Fonseca dos. Literatura de cordel: imagem, memória, tradição. In: Xilogravura: do cordel à galeria, catalogue de l'exposition. João Pessoa, Fundação Espaço Cultural da Paraíba, 1993.

Ecriture de la voix et mémoire du texte: approches actuelles de la littérature populaire brésilienne. In: BERND, Zilá \& MIGOZZI, Jacques (orgs.). Frontières du Littéraire, Littératures orale et populaire Brésil/France. Limoges, Pulim, 1995, p. 33-47.

La littérature de cordel au Brésil: mémoire des voix, grenier d'histoires. Paris, L'Harmattan, 1997.

SILVA, Vera Lúcia de Luna e. Primórdios da literatura popular no Brasil: um folheto de 1865. Seminário Literatura de Cordel: Memória, Vozes, Imagens, 4-6 de novembro de 1993. Programme et livre de résumés. João Pessoa, Funesc, 1993 , p. 23.

SOUZA, Liêdo Maranhão de. Classificação popular da literatura de cordel. Petrópolis, Vozes, 1976.

Ofolheto popular, sua capa e seus ilustradores. Recife, Massangana,

1981.

Idelette Muzart -Fonseca dos Santos é professora da Université de Paris X -Nanterre.

Palestra feita pela autora no Instituto de Estudos Avançados da USP em 24 de agosto de 1999, dentro das atividades do Nupebraf (Núcleo de Pesquisa BrasilFrança). 